\title{
Reincidencia y programas de resocialización en los centros penitenciarios de La Joya y La Joyita
}

\section{Recidivism and Resocialization Programs in the La Joya and La Joyita Prisons}

Omar López Sinisterra * https://orcid.org/0000-0002-4197-1212 http://dx.doi.org/10.21503/lex.v18i26.2196

* Profesor Titular de la Universidad de Panamá. Correo electrónico: tokuterada@yahoo.es

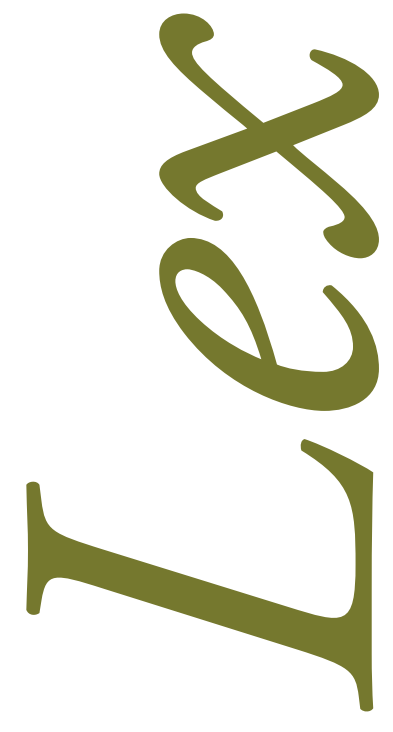




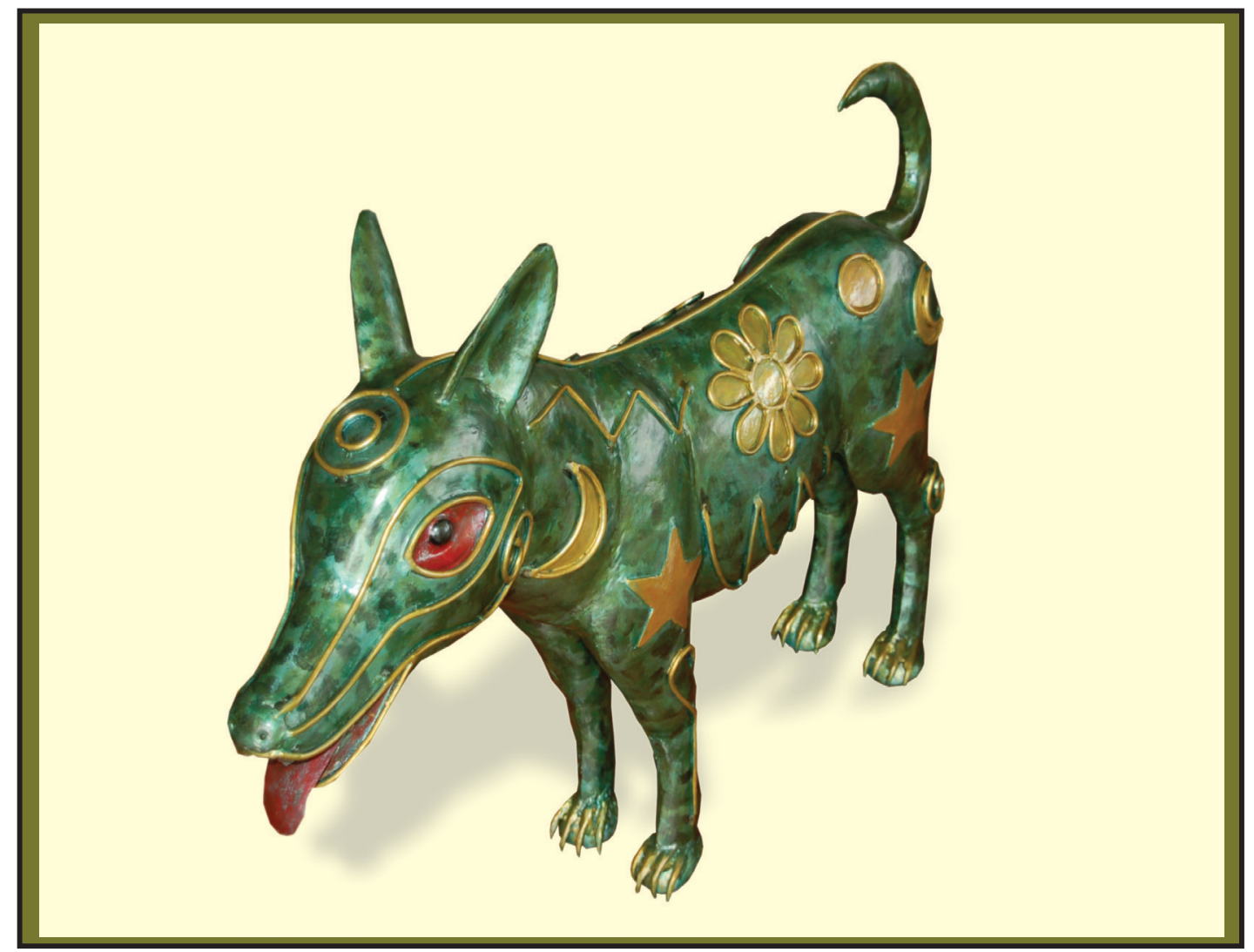

Perro sideral. Hierro y bronce. 2002. Artista plástico peruano, Alberto Quintanilla, (Cusco, 1934). 


\title{
RESUMEN
}

En Panamá, la criminalidad se ha exacerbado aún en los actuales momentos de Pandemia y bajo los efectos del SARS CoV-2 conocido como Covid-19. Inclusive tipos de delitos atroces como el homicidio múltiple de jóvenes y aumento en el feminicidio. El objetivo del presente artículo es el de seńalar el estado de los programas de resocialización en estos centros y su relación con la reincidencia delictiva. Como metodología se utilizó el análisis documental del material concerniente a diferentes eventos que evocan el funcionamiento de estos dos centros y como referente, un trabajo de investigación sobre el tema, realizado en ambos centros penitenciarios por el autor. Un indicador utilizado para medir la disminución de la criminalidad es la reincidencia delictiva, la cual se pretende disminuya a través de innovadores y efectivos programas de resocialización. La implementación de los programas de resocialización en los centros penitenciarios de La Joya y La Joyita tiene como objetivo la reinserción efectiva de los internos que culminan sus condenas para su retorno al entorno social del que provinieron. En estos recintos, los internos se adscriben a diferentes programas vocacionales, deportivos y educativos, los cuales algunos son realizados para adquirir conocimientos, y otros para conmutar o disminuir las penas. Este artículo ha sido realizado con el objeto de analizar los programas de resocialización y su relación con la reincidencia delictiva. Como resultado de este análisis observamos que los programas de resocialización existentes son en realidad pseudo programas, pues no fueron concebidos con los elementos que caracterizan un programa de resocialización. De tal forma concluimos que, al no ser realmente programas de resocialización, se desconoce si se produce la rehabilitación penitenciaria lo cual tiene injerencia o no en el aumento de la reincidencia delictiva.

Palabras clave: reincidencia, criminalidad, programas de resocialización, cárceles.

\begin{abstract}
In Panama, crime has been exacerbated even in the current times of the Pandemic and under the effects of SARS CoV-2 known as Covit-19. Including heinous types of crimes as the multiple homicide of young people and the increase in femicide. The objective of this article is to point out the status of the resocialization programs in these centers and their relationship with criminal recidivism. The methodology used was the documentary analysis of the material concerning different events that evoke the operation of these two centers and as a reference, a research work on the subject, carried out in both prisons by the author. An indicator used to measure the decrease in crime is criminal recidivism, which is intended to decrease through innovative and effective resocialization programs. The implementation of resocialization programs in prisons, in this case in La Joya and La Joyita, has the objective of effectively reintegrating the inmates who complete their sentences and return to the social environment from which they came. In these campuses, inmates are assigned to different vocational, sports and educational programs, some of which are carried out to acquire knowledge, and others to commute or reduce sentences. The article has been written in function to analyze the resocialization programs and their relationship with criminal recidivism. As a result of this analysis, we observe that the existing programs are actually pseudo programs, since they are not really resocialization programs, it is unknown whether prison rehabilitation occurs, which has an influence or not in the increase of criminal recidivism.
\end{abstract}

Key words: reincidence, crimimality, resocialization programs, prisons. 


\section{INTRODUCCIÓN}

La criminalidad en Panamá ha aumentado y diversificado con relación a la cantidad y la calidad de los delitos perpetrados y que afectan nuestra sociedad. Los centros penitenciarios reciben semanalmente cantidades de individuos que han violado las leyes del país. Esto naturalmente tiene injerencia en el hacinamiento y la generación de violencia en estos recintos. Sin embargo, se han creado diferentes programas para poder reinsertar a los egresados del sistema penitenciario una vez cumplidos los requerimientos en cuanto a su condena. En los centros penitenciarios de La Joya y La Joyita, existen programas algunos desarrollados y llevados a efecto por los internos de mayor experiencia como lo son los realizados en el centro penitenciario de La Joyita, y otros un poco más desarrollados y calificados para lograr la resocialización los cuales son conducidos por funcionarios idóneos o por custodios, en espacios cerrados del centro penitenciario La Joya.

En el centro penitenciario La Joyita los programas se llevan a efecto en espacios abiertos y semiabiertos, con equipos rudimentarios pero que tienen resultados en lo que refiere a los productos finales de la gestión generada. Algunos de estos programas son utilizados para autogestión. Los programas vocacionales, deportivos y educativos son altamente valorados por los internos pues les significa que al realizarlos sus penas puedan ser conmutadas o disminuidas.

Si los programas de resocialización no cumplen con el fin propuesto, los internos una vez egresados del sistema vuelven a sus zonas de origen en donde son nuevamente atrapados por las bandas y pandillas generando nuevas acciones delictivas por lo que una vez atrapados, se califican como reincidentes (reincidencia penitenciaria).

Los programas de resocialización en América Latina poseen disimilitudes con los programas existentes en los países nórdicos, en Canadá y otros países anglosajones. Las condiciones de las cárceles y los programas establecidos en estos países permiten que la reinserción social sea efectiva, mientras que, en nuestros países al poseer espacios con gran hacinamiento, no existir control ni seguimiento de los egresados, al ser estigmatizados y no tener posibilidades de empleo, fácilmente reiteran su condición delictiva. 
Señala la UNODC ${ }^{1}$ que "Lo ideal es que los programas institucionales incluyan intervenciones profesionales que puedan reunirse y trabajar con los delincuentes para ayudarles a planificar y preparar su retorno a la comunidad".

\section{El Problema de la Reincidencia Delictiva}

La reincidencia delictiva es un fenómeno que se presenta en el mundo y la cual se caracteriza por la reiteración de un delito el cual puede ser o no de la misma naturaleza que el primero. (Figura No 1)

Los programas de resocialización se constituyen en los indicadores por excelencia de la reincidencia delictiva. Realmente su concepción y estructuración debe realizarse científicamente de tal forma que puedan cumplir con su objetivo primario: la reinserción efectiva de los egresados y que no vuelvan a delinquir

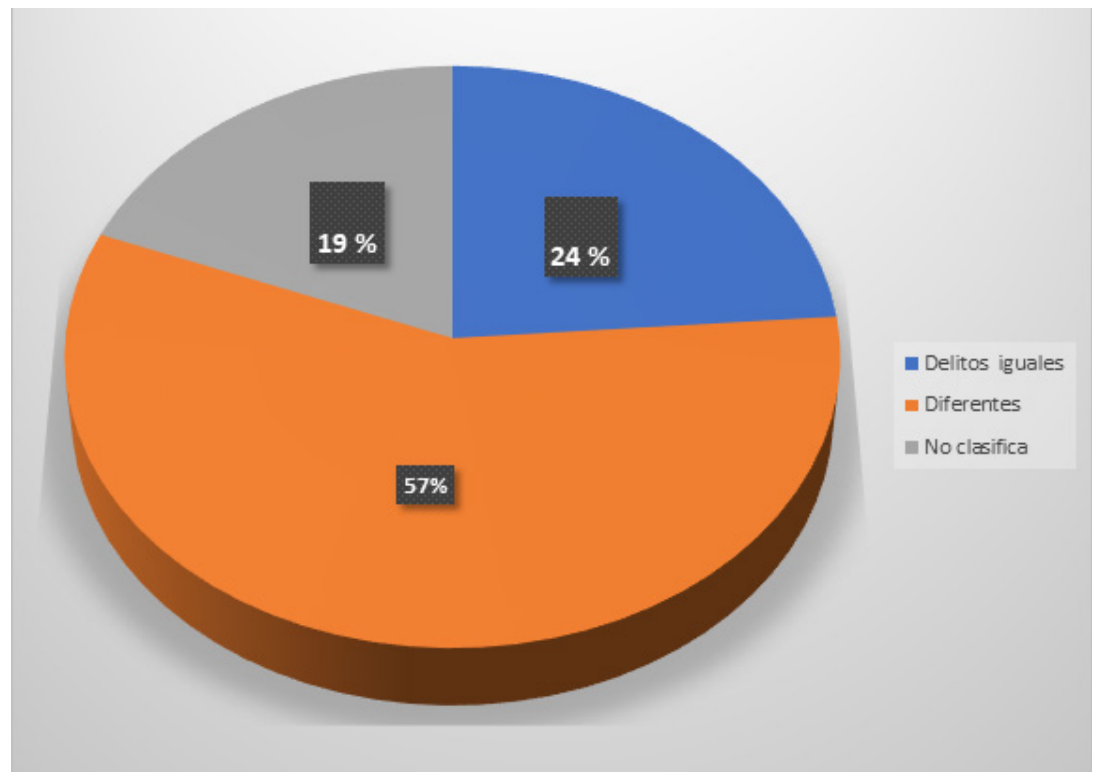

Figura $\mathrm{N}^{\circ} 1$. Reincidencia Delictiva igual o diferente de Internos, Centro Penitenciario La Joya. En esta figura del centro penitenciario la Joya muestra que el 57\% de los internos reincidentes cometen delitos diferentes, el $24 \%$ delitos iguales y el $19 \%$ otros

Fuente: Elaboración propia, 2020

1. UNODC, "Guía de Introducción a la Prevención de la Reincidencia y la Reintegración Social de Delincuentes", acceso el 1 de septiembre de 2020, p. 62.,

https://www.unodc.org/documents/justice-and-prison-reform/UNODC_SocialReintegration_ESP_LR_final_online_ version.pdf 
Es muy difícil medir la reincidencia delictiva puesto que depende de la concepción del problema y que caracterización sea considerada como reincidencia. A este respecto Garzón, Llorente y Suárez², señalan lo siguiente:

"Existen al menos tres aproximaciones de medición: las personas que vuelven a ser capturadas: aquellas que fueron capturadas: aquellas que fueron condenadas por un delito y que, al cometer otro, recibieron el beneficio de la detención domiciliaria o brazalete electrónico, y las que regresaron al sistema penitenciario. Es relevante mencionar que, en sentido estricto, la condena es la que determina la reincidencia probada."

En los centros penitenciarios de La Joya y la Joyita, los delincuentes primarios se mezclan con los reincidentes, con individuos de prontuarios extensos y de peligrosidad, algunos enfermos crónicos y mentales, y ahora con la alta probabilidad de que muchos estén contagiados con el SARS CoV-2 (enfermedad Covid19). Es claro que disminuir el fenómeno de la reincidencia delictiva se hace muy difícil en estas condiciones y con los programas que hay en existencia. $\mathrm{Al}$ respecto López ${ }^{3}$, señala "con respecto a los programas de resocialización, se realizan algunas experiencias en los centros penitenciarios, pero son muy precarios o apoyados por otras instituciones del Estado como INADEH o MEDUCA.”

El Ministerio de Educación implementa los programas educativos en los centros penitenciarios mientras que el Instituto Nacional para el Desarrollo Humano desarrolla los programas vocacionales conocidos como de "resocialización". Los internos en estos dos centros participan de estos programas, pero principalmente porque la Ley les concede la posibilidad de conmutar o disminuir las penas en un tercio de la condena.

Estos programas se realizan en difíciles condiciones en estos centros penitenciarios en donde la infraestructura en el centro penitenciario La Joyita históricamente perteneció a un centro de instrucción militar durante la administración de las fenecidas Fuerzas de Defensa que desaparecieron después de la invasión en 1989 por el ejército norteamericano.

Esta edificación actualmente está deteriorada, enferma y los programas educativos y vocacionales se desarrollan en condiciones no muy favorables existiendo gran deterioro del techado y sanitarios lo que no permite que los profesores realicen sus funciones en condiciones adecuadas. El programa sembrando Paz que es administrado por internos al igual que Eco-Sólidos, rinde frutos que son canalizados como un programa de "autogestión" en el centro. Sembrando Paz tiene como resultado la producción de múltiples plantones de frutales y maderables que se llevan a la venta al igual que ciertos frutos. Eco-Sólidos (Imagen No1) se constituye en un programa de transformación (reciclaje) de plásticos que se utilizan

2. Juan C. Garzón, María V. Llorente, Manuela Suárez, “QQué hacer con la reincidencia delincuencial?” Acceso el 2 de septiembre de 2020,

file://C:/Users/Usuario/Downloads/Que\%20hacer\%20con\%20la\%20reincidencia\%20delincuencial.pdf

3. Omar O. López S., "Análisis de la Reincidencia Delictiva en Panamá: Una Propuesta para un Programa de Resocialización y la Creación del Departamento de Seguimiento al Egresado del Penal Basado en la Teoría Crítica Constructivista", Tesis 2020. p, 247. 
para la construcción de elementos artesanales que pueden ser de utilidad en el hogar y son los de mayor demanda en los centros. (Figura No 2)

En el centro penitenciario La Joya, los programas se realizan en espacios cerrados, tienen iluminación y mejores condiciones estructurales para su realización, pero también son utilizados como programas de autogestión. Existe un programa de sastrería que inclusive posee patente y marca para la fabricación de ropa. El salón de albañilería (Imagen No2) tiene algunos equipos en buen estado que son utilizados para la confección de muebles. También hay un contingente humano que realiza artesanías de muy buen nivel realizadas principalmente por internos extranjeros. Estas artesanías se ha presentado en ferias que han sido realizadas por la Dirección de los centros penitenciarios

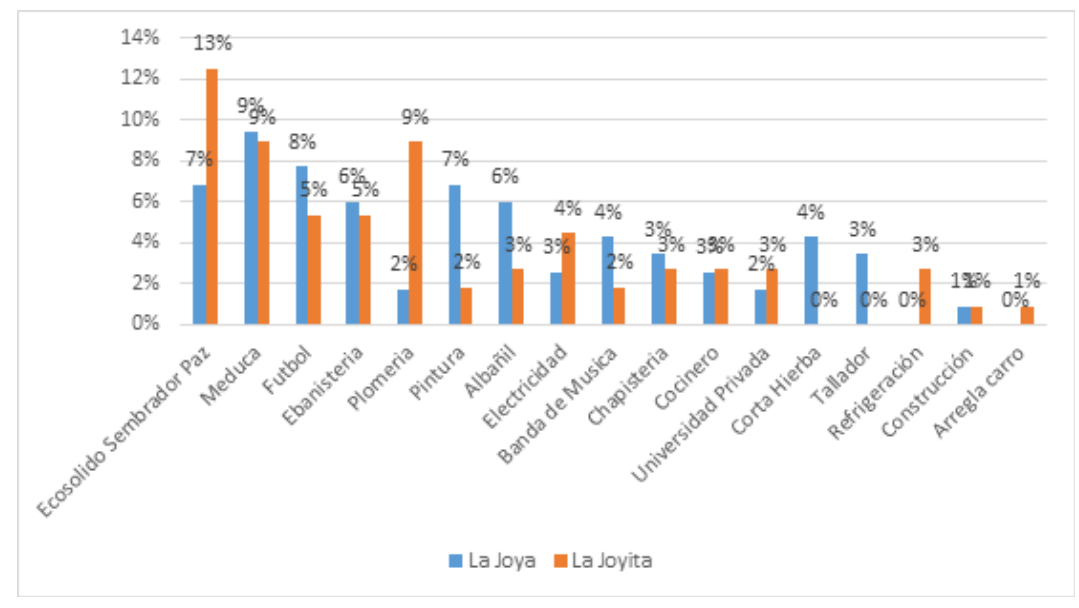

Figura No 2 Presenta los diferentes programas que existen en los centros penitenciarios de la Joya y La Joyita y el porcentaje de participación en ellos por los internos reincidentes. Los programas de Sembrando Paz y Eco Sólidos, Los programas educativos, de ebanistería, fútbol y plomería son los más solicitados.

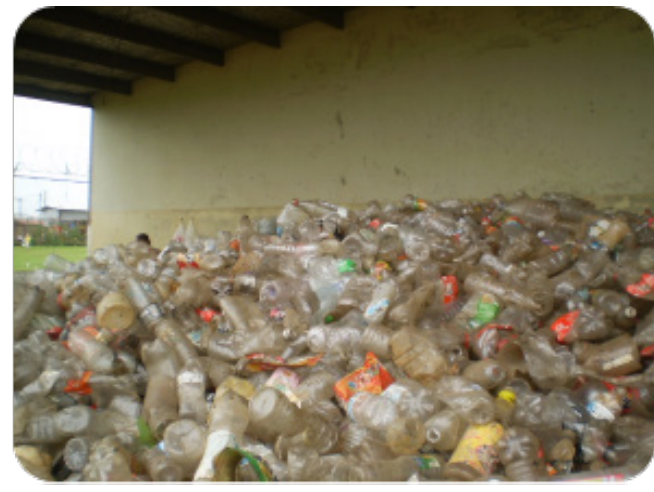

Imagen No1. Plásticos utilizados en el Programa Eco Sólidos

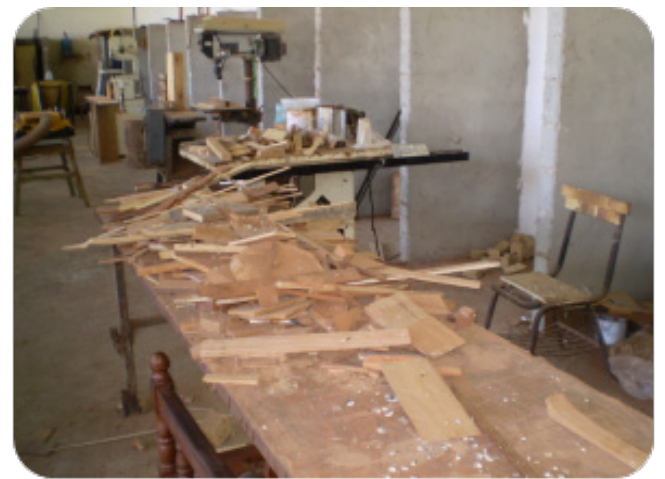

Imagen No2. Programa de Ebanistería Centro Penitenciario La Joyita Centro Penitenciario La Joya 


\section{PROGRAMAS DE RESOCIALIZACIÓN VERSUS EL HACINAMIENTO, EL OCIO Y LA VIOLENCIA}

Cómo poder obtener resultados positivos en la resocialización a través de los programas existentes si en estos centros penitenciarios existe el régimen informal que han desarrollado bandas y pandillas y que tienen marcada injerencia sobre quiénes pretendan acceder a los diferentes programas. La Ley del más fuerte ejercida a través de diferentes organizaciones criminales con nexos externos, rivaliza con el ordenamiento formal que existe en estos centros. Su fortaleza y ejercicio en la toma de decisiones en los recintos, se evidencia en la influencia sobre los internos, sobre quiénes participan en los programas y quiénes son subordinados al imperio de su Ley.

En algunos países se están utilizando modalidades que tienden a reducir la cantidad de individuos que son procesados tales como el trabajo comunitario, la restauración, y otros, debido al grave problema del hacinamiento. Otros han construido cárceles con ambientes favorables y armónicos con el medio ambiente y social preservando los mecanismos de seguridad existentes. De esta forma lo puntualiza la autora Rincón ${ }^{4}$ señalando que:

"De igual forma se refuerza la idea que la solución no está en construcciones masivas, desbordadas especialmente en ciudades penitenciarias aisladas de los servicios urbanos, sino por el contrario modelos arquitectónicos urbanísticos armonizados con el entorno social, por supuesto con seguridad de niveles, pero presente en el inconsciente como en el consciente social, lo que permite realizar apoyos y servicios desde lo urbano pensando en la reinserción de ese ser humano a la sociedad."

Sin embargo, siguen los procesos judiciales adjudicando detenciones preventivas y acumulando cantidades de internos en nuestras cárceles.

Muchos delincuentes primarios terminan en la escuela para el crimen en donde los internos de mayor experiencia los instruyen para la mejora de sus habilidades utilizadas en la comisión de ilícitos y para obedecer los lineamientos de las organizaciones criminales. Así lo señala el diario La Estrella de Panamás cuando puntualiza que:

"Más de un 60\% de la población encarcelada no le ha visto aún la cara a un juez y abarrota nuestras prisiones, muchas veces por un tiempo superior de habérsele encontrado culpable. El hacinamiento evidentemente tiene una simple solución, sin necesidad de más cárceles. Aunado a esto es que aquí en Panamá sentenciamos al presidio casi 10 veces más que en otras latitudes, cuando existen otras alternativas, tales como las multas, extenso servicio a la comunidad sin remuneración y sentencias más cortas.”

4. Yomaira Rincón Rodríguez, "El Hacinamiento en el Sistema Penitenciario y Carcelario Colombiano”, p. 12, acceso el 2 de septiembre de 2020, repository.unimilitar.edu.co

5. La Estrella de Panamá, "Nuestras Cárceles y su hacinamiento", p.1, acceso el 3 de septiembre de 2020, laestrella.com.pa/opinión/redacción-digital-la-estrella/131229/cárceles-hacinamiento 
Es importante también considerar en el marco de las estructuras penitenciarias, la distribución científica de los internos en función de variables como la edad, reincidencia, delitos primarios, enfermedades presentes, alta peligrosidad, antecedentes, lugar de procedencia etc. Se pueden diseñar espacios con estos determinantes aislados los unos de los otros con sus zonas de esparcimiento y programas de resocialización y educativos dirigidos a cada grupo de estos internos. El tratamiento dirigido especialmente a cada uno de estos grupos puede permitir un proceso de resocialización exitoso.

También debemos controlar el egreso de los internos mediante un departamento que esté dirigido a este fin para el seguimiento por medio de tutores y reinsertándolos en zonas que estén libres de la influencia de bandas y pandillas que los puedan reclutar. La carencia de estos procesos por supuesto que va a generar un mayor ingreso de individuos por la razón que al salir de los centros penitenciarios, se encuentran sin soluciones laborales y con el estigma del récord policivo.

Si el ordenamiento en los centros por parte de las autoridades no se hace presente y si no se estructuran buenos y efectivos programas de resocialización en los centros, aumenta el ocio y el régimen de violencia con resultados que irrumpen en el equilibrio del sistema.

Las organizaciones criminales extienden sus largos brazos para incidir en los administradores, custodios y policías en los centros, de tal forma que logran sus principales objetivos, entre ellos la evasión, el contrabando de armas y drogas, y el dominio en el recinto.

El hacinamiento existe en los centros de La Joya y La Joyita. Poseen galeras que albergan entre 300 y hasta 500 internos en las peores condiciones de vida y que violentan las reglas mínimas para los reclusos de las Naciones Unidas. Esta situación existente se constituye en una clara violación a los Derechos Humanos. Son áreas físicas totalmente contaminadas. Entre ellas corren aguas negras con olores muy desagradables. Los sanitarios existentes para los internos están en condiciones deplorables y son pocos para la gran cantidad de ellos en sobrepoblación. También existe la carencia frecuente de agua potable en estos centros y se les dispensa por medio de tanque cisterna.

Los programas de resocialización como hemos descrito con antelación son utilizados como un medio para disminuir las penas y salir de los centros penitenciarios. Para algunos internos si representa una forma de adquirir conocimientos y experiencias que les servirán para poder constituirse en seres socio productivos en una sociedad que está lejos de motivarse por los problemas que acaecen en estos centros. Los programas educativos son de gran ayuda para los internos y a nivel universitario se han realizado experiencias a través de módulos y con universidades privadas. Se han realizado experiencias a nivel de la Universidad de Panamá y el Centro Penitenciario Femenino, que han sido muy positivas y de las cuales han egresado profesionales. Esta experiencia se ha realizado en el Centro Regional de San Miguelito (CRUSAN) en la provincia de Panamá. 


\section{CORRUPCIÓN EN ESTAS CÁRCELES}

En la última década se han presentado casos de corrupción en los centros penitenciarios de La Joya y La Joyita. Han estado involucrados desde directores, custodios, comisionados y oficiales de policía. Desde evasión de internos de alto perfil, hasta la introducción de contenedores con armas y equipos electrónicos en los centros. Se evidencia la situación de introducción de armas con diferentes hechos de amotinamiento y muertes de individuos como resultado de la rivalidad entre pandillas y la lucha por el poder a lo interno de las cárceles. En diciembre de 2019 en el centro penitenciario La Joyita ocurrió una disputa entre elementos de una misma pandilla y que utilizaron armas cortas y largas producto del contrabando. El resultado: 12 muertos y 13 heridos. Según la BBC News Mundo "el penal es el más poblado del país con 3,733 presos y una sobrepoblación de 896 personas, según estadísticas oficiales recogidas por la agencia Efe".

Las autoridades y administrativos en los centros de La Joya y La Joyita se encuentran relacionados de forma directa con los internos, de tal forma que existe una relación directa y cercana entre ellos lo que facilita el escenario de la corrupción.

Se han producido casos de evasión con la compra de autoridades de los centros y los cuales han sido detectados y procesados por estos delitos. El 14 de junio de 2018 se evadió del centro penitenciario La Joyita el israelí Shy Dahan, hecho en el que "se encontraron siete involucrados por la presunta comisión del delito de peculado, falsificación de documentos e infracción de los deberes de los servidores públicos” según la redacción de noticias de Televisora Nacional

Canal $2^{7}$. Estos casos se han realizado en muchas ocasiones y realmente se deben tomar medidas enérgicas para la mejora de la distribución arquitectónica carcelaria de las autoridades y administrativos, como también de los internos entre otras.

Para obtener un personal idóneo y adecuado que lleve a efecto un buen funcionamiento de estos centros debe existir capacitación permanente, buena remuneración de los funcionarios, una inducción permanente en materia de valores y principios con una férrea selección del personal que en ellos va a laborar. Además de una estructuración científica de los centros y la estructuración de excelentes programas de resocialización con dirección personalizada en función de los diferentes perfiles de los internos.

En los actuales momentos frente al temor del contagio por el Covid 19, existe mucha inquietud entre el personal de los centros penitenciarios y los internos, los cuales en algunos casos se han manifes-

6. BBC News Mundo, "Balacera en la Joyita: al menos 12 muertos y 13 heridos en una reyerta en la controvertida cárcel de la ciudad de Panamá", p. 3, acceso el 3 de septiembre de 2020. bbc.com/mundo/noticias-america-latina-50818486

7. TVN-Canal 2, "Implicados por evasión del israelí de la Joyita enfrentan audiencia intermedia este lunes", acceso el 4 de septiembre de 2020, p.1,

tvn-2.com/nacionales/judicial/Implicados-evasion/enfrentaron-audiencia-intermedia-La-Joyita_0_5427207267.html 
tado al respecto. Ya se han detectado muchos casos de Covid 19 tanto en las cárceles de la ciudad como en el interior del país. Y es que las condiciones de hacinamiento e insalubridad propician el contagio de esta enfermedad que ya ha cobrado más de 2,000 muertes en el país.

\section{VOLUNTAD POLÍTICA Y UN BUEN PRESUPUESTO}

Los presupuestos otorgados históricamente a los centros penitenciarios se han utilizado para funcionamiento y establecimiento de algunos programas. En algunos gobiernos se han creado nuevas cárceles y sin embargo el problema sigue en aumento. Se necesita de voluntad política para establecer nuevas políticas, planes y estrategias para disminuir la criminalidad y mejorar los centros penitenciarios disminuyendo la reincidencia delictiva a través de buenos y efectivos programas de resocialización. También es necesario crear departamentos de seguimiento de los egresados y llevar una estadística real y actualizada de los casos de reincidencia, drogadicción, enfermedades crónicas, mentales y darle el tratamiento electivo. En la actualidad bajo la Pandemia, se hace muy difícil mejorar el sistema penitenciario pues la economía está gravemente afectada y una gran cantidad de esfuerzos están dirigidos al área de la salud como prioridad por los efectos de esta enfermedad. Si en condiciones normales existían muchos problemas en estos centros penitenciarios, con la afectación de la economía y racionalización presupuestaria, los problemas seguirán en un escenario de un incremento sensible de la criminalidad en el país.

Muchos autores han señalado que los programas de resocialización han fracasado y sin embargo en otros países han resultado exitosos porque en ellos existe una mejor distribución de la riqueza y poseen establecimientos carcelarios de mejor nivel y diferentes programas de restauración y conciliación entre las víctimas y los victimarios, además la sociedad está más comprometida para rehabilitar a aquellos que han cometido acciones delictivas.

\section{CONCLUSIONES}

Los centros penitenciarios de La Joya y La Joyita en la Provincia de Panamá son las instituciones penitenciarias con mayor número de internos en el país. De estos internos muchos son reincidentes cumpliendo condenas por diversos delitos. Estos centros poseen estructuras muy deterioradas y enfermas con contaminación en las cuales existe gran hacinamiento y cuadros de violencia. Existen diversos programas de "resocialización" que tienen como fin la reinserción social de los internos como entes socialmente productivos. Existen programas muy precarios en el centro penitenciario La Joyita que son administrados por internos tales como Eco Sólidos y Sembrando Paz, mientras que en el centro penitenciario La Joya los programas poseen equipos en mejores condiciones, pero son administrados por el personal custodio. Entre ellos hay programas de albañilería, sastrería, artesanías, y carpintería que son también utilizados para autogestión. Las condiciones de vida en estos centros riñen con las reglas mínimas de reclusión de las Naciones Unidas y con los Derechos Humanos. En estos centros hay historia de corrupción entre sus funcionarios lo que ha permitido la presencia de armas, motines, muertes y la evasión de internos de alto perfil. Los programas educativos se llevan a efecto en áreas muy deterioradas 
en su estructura y en condiciones muy difíciles para los funcionarios. El presupuesto a través de los diferentes gobiernos ha sido escaso para el funcionamiento sin que realmente se haya podido estructurar edificaciones construidas científicamente y en las cuales no exista hacinamiento, ni programas que permitan la resocialización efectiva y la reinserción social de los internos con el seguimiento y controles necesarios. Actualmente y en medio de la Pandemia por el Covid 19, se han incrementado los casos de contagio los cuales se constituyen en reservorios importantes dadas las condiciones existentes y en una economía que ha sido muy golpeada debido a la actual situación. El panorama es muy difícil para los internos en los centros penitenciarios y para el desarrollo de los programas de resocialización. Las mejoras que puedan realizarse en los centros son dependientes de la voluntad política de los gobernantes, la asignación de un buen presupuesto y la modernización de estructuras presentes y la construcción de nuevos centros, pero de forma científica en toda su concepción. Las mejoras deben ser integrales en función de mejores programas, capacitación permanente del personal, distanciamiento entre administrativos e internos, mejor distribución de los internos a través de nuevas estructuras, contratación de personal idóneo en los programas, y una mejor seguridad.

\section{REFERENCIAS}

- UNODC. "Guía de Introducción a la Prevención de la Reincidencia y la Reintegración Social de Delincuentes”. 2013. (Guía electrónica). Acceso el 1 de septiembre de 2020 desde, https://www.unodc.org/documents/justice-and-prison-reform/UNODC_SocialReintegration_ESP_ LR_final_online_version.pdf

- Garzón, Juan C., Llorente, María V., Suárez, Manuela. “¿Qué hacer con la reincidencia delincuencial?”. Fundación de Ideas para la Paz. (Artículo electrónico), 2018. Acceso el 2 de septiembre de 2020 desde file://C:/Users/Usuario/Downloads/Que\%20hacer\%20con\%20la\%20reincidencia\%20 delincuencial.pdf

- López S., Omar O., "La Reincidencia Delictiva en Panamá: Una Propuesta para un Programa de Resocialización y la Creación del Departamento de Seguimiento al Egresado del Penal Basado en la Teoría Crítica Constructivista”. Investigación Descriptiva Transversal y Correlacional, Universidad Iberoamericana, México, 2020.

- $\quad$ Rincón R., Yomaira. "El Hacinamiento en el Sistema Penitenciario y Carcelario Colombiano”. 2014. Universidad Militar Granada. (Versión electrónica). Acceso el 2 de septiembre de 2020 desde repository.unimilitar.edu.co/bitstream/handle/10654/13151/PROYECTO $\% 20$ HACINAMIENTO.pdf.jsessionid=7D99F96AE1842E43EC2C461C59A647E?sequence=1

- La Estrella de Panamá. Diario. "Nuestras Cárceles y su Hacinamiento”. 2013. (Artículo electrónico). Acceso el 3 de septiembre de 2020 desde la estrella.com.pa/opinión/redacción-digital-la-estrella/131229/cárceles-hacinamiento 
BBC News Mundo. "Balacera en la Joyita: al menos 12 muertos y 13 heridos en una reyerta en la controvertida cárcel de la ciudad de Panamá”. 2019. (Artículo electrónico). Acceso el 3 de septiembre desde bbc.com/mundo/noticias-America-Latina-50818486

- $\quad$ TVN Canal 2. "Implicados por evasión del israelí de La Joyita enfrentan audiencia intermedia este lunes". 2019. (Artículo electrónico). Acceso el 4 de septiembre desde, tvn-2.com/nacionales/judicial/Implicados-evasion-enfrentaron-audiencia-intermedia-LaJoyita_0_5427207267.html

RECIBIDO: $10 / 09 / 2020$

APROBADO: $25 / 10 / 2020$ 


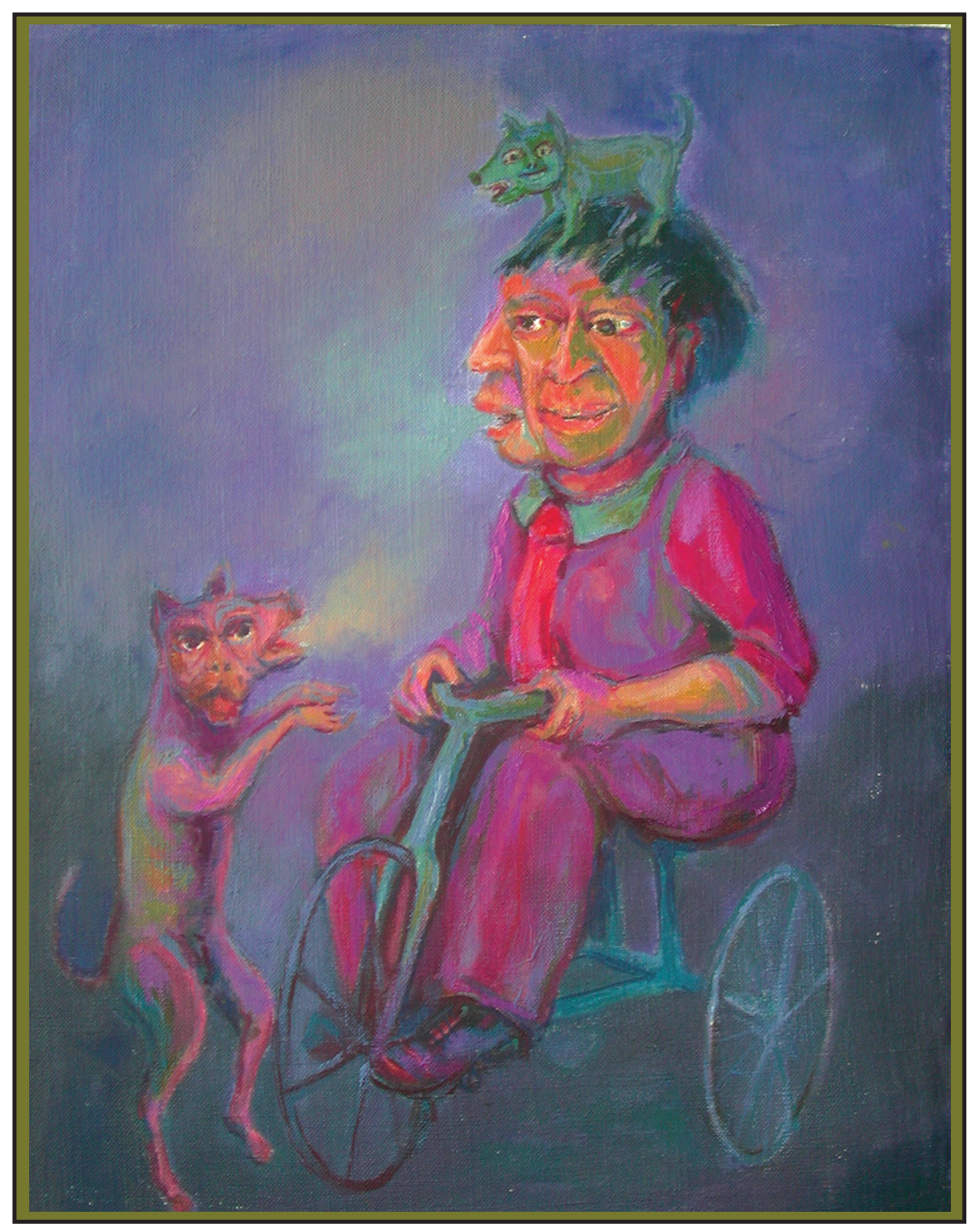

Payaso. Óleo, 1999. Artista plástico peruano, Alberto Quintanilla, (Cusco, 1934). 